\title{
Sturm und Drang na música para teclado de Wilhelm Friedemann Bach: evidências reveladas na Polonaise No.4 em Ré menor
}

\author{
Stella Almeida Rosa (UNICAMP, Campinas, SP) \\ stellaalmeidarosa@gmail.com
}

Helena Jank (UNICAMP, Campinas, SP)

hjank@iar.unicamp.br

Resumo: Este trabalho propõe-se a revelar elementos contextuais e musicais, especialmente aqueles ligados à expressividade, que aproximem a obra para teclado de Wilhelm Friedemann Bach ao movimento Sturm und Drang, ocorrido na Alemanha no início da segunda metade do século XVIII, através do reconhecimento dos procedimentos literários e musicais envolvidos e da análise da Polonaise $n^{\circ} 4$, em Ré menor, como obra representativa do que se pretende demonstrar. Palavras-chave: teclado; Bach, W. F.; estilos musicais; expressividade.

\section{Sturm und Drang in the keyboard music of Wilhelm Friedemann Bach: detected evidences in Polonaise N.4, in D minor}

Abstract: This paper intends to point out contextual and musical elements, especially those relative to expressiveness, that brings Wilhelm Friedemann Bach's keyboard works close to German Sturm und Drang, that happened during the beginning of the second half of the eighteenth century, through the identification of the literary and musical procedures and the analysis of the Polonaise number 4, in D minor, as a representative work of this style.

Keywords: keyboard; Bach, W. F.; musical styles; expressiveness.

\section{Introdução e objetivos}

Como filho mais velho e depositário das mais altas expectativas de Johann Sebastian Bach em relação ao futuro musical da família, Wilhelm Friedemann (1710-1784) não poderia ter deixado de experimentar sentimentos de ansiedade e incerteza, provenientes da responsabilidade naturalmente a ele atribuída por essa condição. Reflexos dessa instabilidade parecem ter sido levados para sua música, carregada de inquietação e alternância entre o velho e o novo, entre a tradição herdada e solidificada pela formação diretamente recebida do pai e a possibilidade emergente de uma expressão trazida pelas novas correntes de pensamento que percorreram a Europa em meados do século XVIII. HELM (1983) aponta esses fatores como responsáveis pelo fato de que, apesar de reconhecido como compositor talentoso, não tenha desenvolvido completamente seu potencial criativo.
Friedemann demonstrou desde cedo sua natural inclinação para os instrumentos de teclado, e um rápido olhar sobre o Clavier-Büchlein, a ele dedicado pelo pai quando contava dez anos, faz notar sua rápida evolução. A instrução formal na Thomasschule de Leipzig não interferiu na continuidade de sua educação musical, que incluiu também o violino. Mais tarde, na Universidade de Leipzig estudou matemática, filosofia e direito.

Ao assumir em 1733 o posto de organista na Sophienkirche em Dresden, conviveu com a fartura de espetáculos de ópera e balé apresentados naquela então rica e efervescente corte, além de travar amizade com artistas e intelectuais que por lá circulavam. Porém, como organista protestante e ligado ainda à tradição contrapontística, Friedemann acabou por se reconhecer deslocado numa corte católica onde predominava o gosto pela ópera. Em 
1746 assumiu o posto de organista e Director Musices da Liebfrauenkirche, na corte pietista ${ }^{1}$ de Halle. Ainda que as condições de trabalho fossem superiores às de Dresden, e que houvesse lá um ambiente intelectual e musical mais favorável ao desenvolvimento de seu trabalho, Friedemann teve grande dificuldade em se adaptar à sociedade moralista e de tendências ascéticas da cidade. Depois de dezoito anos de trabalho, reconhecido como o maior organista da Alemanha, renuncia ao seu posto, não assumindo mais nenhum cargo até o fim da vida e tornandose assim um dos primeiros compositores independentes em atividade na segunda metade do século XVIII.

Esse texto busca apontar, após o exame do histórico de vida, formação e do estilo musical de Friedemann - que constroem um quadro bastante particular dentro do padrão de compositores seus contemporâneos -, e ao lado da compreensão do contexto estético e musical dos estilos que vigoravam em meados do século XVIII, elementos que demonstrem sua identificação com o universo carregado de drama, sensibilidade e inovação musical que caracterizou a música do norte da Alemanha nesse período.

\section{Fundamentação teórica}

Para a contextualização musical do período histórico tratado neste trabalho e dos estilos musicais propriamente ditos, foram utilizados os autores Downs (1992), Pauly (2000) e Van Ess (1970), além do relato histórico de Burney (1775). Como mais fundamentado e sistemático autor a abordar a obra de W. F. Bach atualmente, Wollny $(2001,2003)$ é a principal fonte teórica a respeito da sua obra para teclado.

\section{Empfindsamer Stil e o Sturm und Drang}

Segundo VAN ESS (1970), a leveza de mentalidade rococó característica do estilo galant francês, disseminada em toda Europa pelos ventos do lluminismo, estava presente também na música produzida na Alemanha. 0 espírito germânico ocasionou, no entanto, o surgimento de uma nova estética, através da inserção de um novo elemento, que a razão e a elegância da música francesa procuravam domar: a emoção humana. Mais recentemente, corroborando essa opinião, PAULY (2000) observa que, ainda que a influência francesa fosse sentida na Alemanha - Frederico II chegou a receber Voltaire em Potsdam para longos colóquios -, foi nesse período que emergiu o estilo germânico na música. Assim, por volta de 1740, tendo como mais ilustre representante o irmão mais novo de Wilhelm Friedemann, Carl Philipp Emmanuel Bach, mas também seus contemporâneos de Manheim, Berlim e Viena, vigorou no norte da Alemanha o Empfindsamer Stil (estilo sensível) ${ }^{2}$.

A respeito do auge dessa prática, diz William J. Mitchell, o tradutor e editor da versão inglesa do Versuch über die wahre Art das Clavier zu spielen (1762), de C. Ph. E. Bach:

\footnotetext{
...Bach fez da mestria técnica do teclado apenas um elemento de contribuição para o final expressivo que ele buscava. A música aqui está muito afastada de uma arte decorativa, de padrões abs-
}

tratos de som; ela era, acima de tudo, um veículo para a expressão das emoções. A música deve suspirar, deve surpreender, deve alegrar, deve mover-se audaciosamente de um sentimento para outro; esses eram os requisitos que deviam ser contemplados pelo compositor. (Mitchell, 1949, p.16).

Importantes observações sobre a expressão musical em vigor na Alemanha desse período foram fornecidas por Charles Burney em seu livro The Present State of Music in Germany, the Netherlands and the United Provinces, de 1775. No capítulo referente à sua estada em Potsdam, Burney relata as seguintes impressões ao descrever a execução de um solo de violino de Benda: ${ }^{3}$

\footnotetext{
Seu estilo é tão verdadeiramente cantabile, que dificilmente uma passagem pode ser ouvida em suas composições, que não seja possível para a voz humana cantá-la; e ele toca com tanta emoção, tão pateticamente um Adagio, que muitos professores asseguraram-me que tem frequentemente lhes arrancado lágrimas ao executar um [Adagio].(Burney, 1775, p.129). ${ }^{4}$
}

Nota-se que a sentimentalidade estava presente em toda Europa em meados do século XVIII, da literatura inglesa (Sentimental Journey, de Sterne, de1768, foi um dos icones) aos Concerts des amateurs em Paris, onde Forkel narra, no seu Musikalisch-kritische Bibliothek de 1778, um ensaio "no qual os músicos estavam tão tomados pela emoção que depuseram seus instrumentos e deram livre vazão ao seu pranto" (in PAULY, 2000, p.24). Na Alemanha, porém, a sentimentalidade ganha contornos específicos que vão além da elegância e do refinamento melódico do estilo galante. Estes aparecem na música através da ênfase nas mudanças súbitas, sejam de caráter dentro de um mesmo movimento de uma obra, da variedade de padrões rítmicos ou do fraseado, e, seguindo a tradição germânica, que sempre cultivou a música cantada através dos coros e do hábito da hausmusik, por seguir o modelo da voz humana, como afirmou Carl Phillip no Versuch...

A intensificação da Empfindsamkeit e seus efeitos corresponde ao surgimento do movimento intenso e de curta duração - aproximadamente de 1760/70 a meados da década de 1780 - que foi o Sturm und Drang (tempestade e impeto). Esse nome foi cunhado em virtude de uma peça de Friedrich Maximilian Klinger (1752-1831), embora antes dela já houvesse muitas manifestações artísticas e literárias enquadradas nessa estética. Segundo ROSENFELD (1993), "é um movimento rebelde, empenhado pela emancipação das letras nacionais, que joga o inconsciente e a inspiração do "gênio original" contra o intelecto e o gosto crítico do "artista". Impulsionados pelas teorias de genialidade, pela admiração por Shakespeare, pelos escritos de Rousseau e por sagas místicas e de inspiração nórdica, os artistas dessa corrente foram responsáveis pelas primeiras manifestações pré-românticas que apareceram na Europa. Como expressão máxima dessa estética, carregada de impulso, explosão e dor, considera-se, na literatura, as obras de Goethe Götz Von Berlinchingen (1773) e Die Leiden des jungen Werthers (1774), e de Schiller Die Räuber (1780-81). Na música, as principais manifestações do estilo são encontradas na obra de C. Ph.E. Bach 
e seus contemporâneos Johann Gottfried Müthel (17281788) - que foi aluno de J.S.Bach -, e Johann Gottfried Eckard (1735-1809), e em determinadas sinfonias e quartetos de cordas de Haydn e Mozart, de fase anterior à plenitude do classicismo.

Foi na música para teclado que o Sturm und Drang encontrou o meio mais fértil e direto de expressão, combinando a valorização da genialidade e das manifestações individuais com as várias possibilidades técnicas surgidas com o advento do fortepiano. Esse instrumento permitia a mudança brusca de graduações dinâmicas, um dos anseios expressivos do período, mas é importante notar que o cravo e o clavicórdio continuaram a ser usados regularmente como intérpretes da música dos compositores do período. 0 clavicórdio poderia ter sido o grande divulgador dessa música, pois além da possibilidade de alternância de planos dinâmicos, é capaz de realizar efeitos como o vibrato. No entanto, seu pequeno volume de som restringia sua utilização a ambientes intimistas, justamente em um período no qual a música começava a tornar-se um espetáculo para platéias maiores, e, ao mesmo tempo, não seria capaz de suportar o ímpeto e a necessidade de sonoridade intensa necessários a obras de Carl Phillip e outros compositores, como é o caso de Wilhelm Friedemann. Julia Brown cita, nos comentários do seu registro das Fantasias e Fugas de Friedemann (2007), um relato de 1774 sobre suas apresentações públicas: "tinham exatamente os ingredientes para colocar em evidência o pulso firme, idéias novas, bruscas mudanças de tonalidade, movimentos dissonantes..." E, como comenta SAGHAARD (2001) no seu trabalho sobre os estilos musicais na obra para teclado de Carl Phillip, "a música para teclado alemã foi responsável, mais que a italiana, por levar a arte dos sons a uma ruptura enfatizando uma força de criação mais subjetiva".

\section{Friedemann, suas Polonaises e o Sturm und Drang}

Explosões emocionais, intensidade harmônica marcada por cromatismo e passagens enarmônicas, acordes aumentados, modulações para tons distantes, "recitativos" instrumentais intercalando passagens melódicas, frases curtas, interrupções, são características descritas por autores como DOWNS (1992), PAULY (2000) e VAN ESSS (1970), para a música dos compositores identificados com o Sturm und Drang. Consequentemente, olhando-se para a coleção das Zwölf Polonaisen $(1765)^{5}$, especialmente para a peça proposta nesse trabalho, a Polonaise em Ré menor, não é difícil identificá-la com tais características.

Wilhelm Friedemann tem sido por décadas - talvez séculos, se considerarmos que mesmo os historiadores dos séculos XVIII e XIX não se ocuparam sistematicamente de sua produção - considerado um "maldito", um compositor de certa forma exótico, devido às peculiaridades e estranhezas de sua música e de sua personalidade, tornadas públicas através de cartas e relatos de músicos da época, como Marpurg (1718-1795) e Reichardt (1720-1780). 0 citado livro de Burney, por exemplo, escrito na época em que Friedemann já havia deixado Halle, mas gozava de reputação única como organista, não faz menção às suas composições. Embora Martin Falck (1888-1914) tenha realizado o catálogo de suas obras e publicado, em 1913, seu livro até hoje referencial sobre 0 autor $^{6}$, só recentemente, em fins do século XX e na presente década, é que sua música - e mais especificamente, a música para teclado - vem recebendo maior atenção por parte de intérpretes e musicólogos.

Peter Wollny, autor das obras atuais mais sistemáticas sobre o compositor, aponta, em artigo publicado em 2003, no livro editado por Christopher Hogwood em comemoração aos 75 anos de Gustav Leonhardt, ${ }^{7}$ para a naturalidade e ao mesmo tempo originalidade da escolha dessa forma, a Polonaise, e a conseqüente popularidade que esse conjunto de peças alcançou na época. ${ }^{8}$ As formas curtas de dança estavam muito presentes na segunda metade do século XVIII e se prestavam eficientemente à expressão das novas idéias e procedimentos peculiares dos estilos em vigor, como frases curtas e mudanças bruscas. Reuni-las em uma coleção - e não individualmente fazendo parte de uma suíte - não chega a ser uma inovação para o período, pois como observado pelo mesmo autor, assim o fizeram Goldberg, Ziegler e Kirnberger, mas possivelmente remete também ao apego de Friedemann por sua formação polifônica, dando às suas Polonaises uma sequência tonal semelhante às Invenções e Sinfonias compostas por seu pai. Paralelamente, ele imprime a elas uma estilização do padrão de dança característico da forma Polonaise, como já havia observado BÖHNERT (1993) e reitera WOLLNY (2003).

A quarta Polonaise, em Ré menor, é a peça mais curta da coleção. Tem apenas dezesseis compassos, ou trinta e dois, se consideradas as repetições. HILL (2005), no encarte de sua gravação referencial desse conjunto, atribui à número 4 a alcunha de "Weberiana", tal sua capacidade de sintetizar a idéia a ser transmitida e de utilizar com habilidade a desorientação harmônica como elemento expressivo. Esse efeito ocorre nos compassos 2 e 4 (Ex.1).

No compasso 2, o encaminhamento harmônico esperado é de um acorde diminuto (Do sustenido, Mi, Sol, Si bemol). Surpreendentemente, surge Mi bemol no lugar de Mi natural, sugerindo uma harmonia de Mi bemol maior que depois não chega a se configurar e causando o efeito de instabilidade. No compasso 4 o mesmo processo se repete, dessa vez na subdominante (Sol menor, que deveria ir para Fá sustenido diminuto, mas aparece o La bemol sugerindo La bemol maior, que não acontece). Observando que em termos de forma essa miniatura é absolutamente tradicional, com períodos de oito compassos, motivo de dois compassos que se repete e sequência de quatro compassos que se encaminha para a cadência, harmonicamente é notável e enquadra-se no tipo de procedimento e resultado buscado pelos compositores do Sturm und Drang. Os intervalos melódicos de sexta ascendente e descendente presentes nos compassos 1, 3, 5 e 6, seguidos de síncope, também são elementos fortemente expressivos - 0 intervalo de sex- 

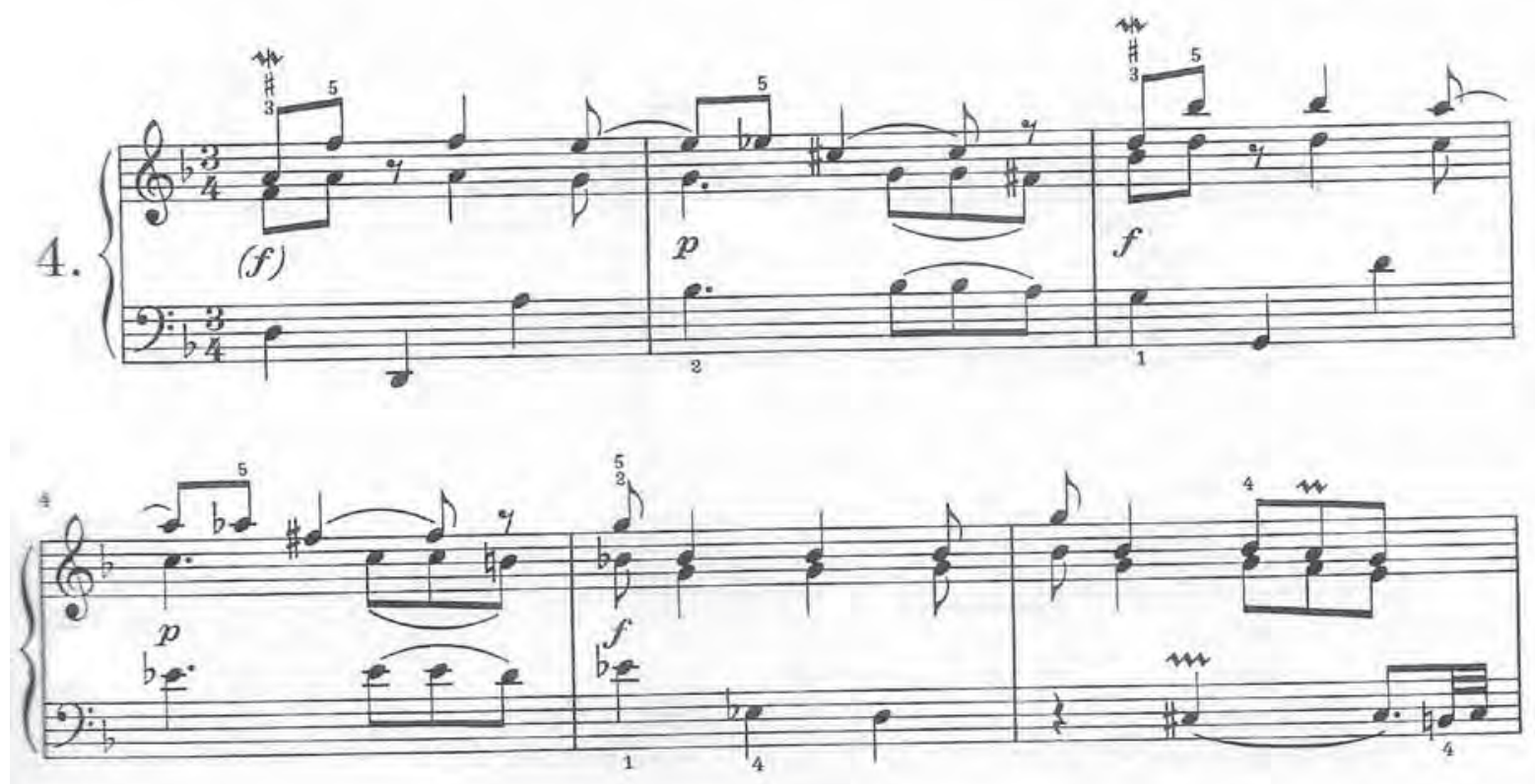

Ex.1: Wilhelm Friedemann, Polonaise, em Ré menor, c.1-6.
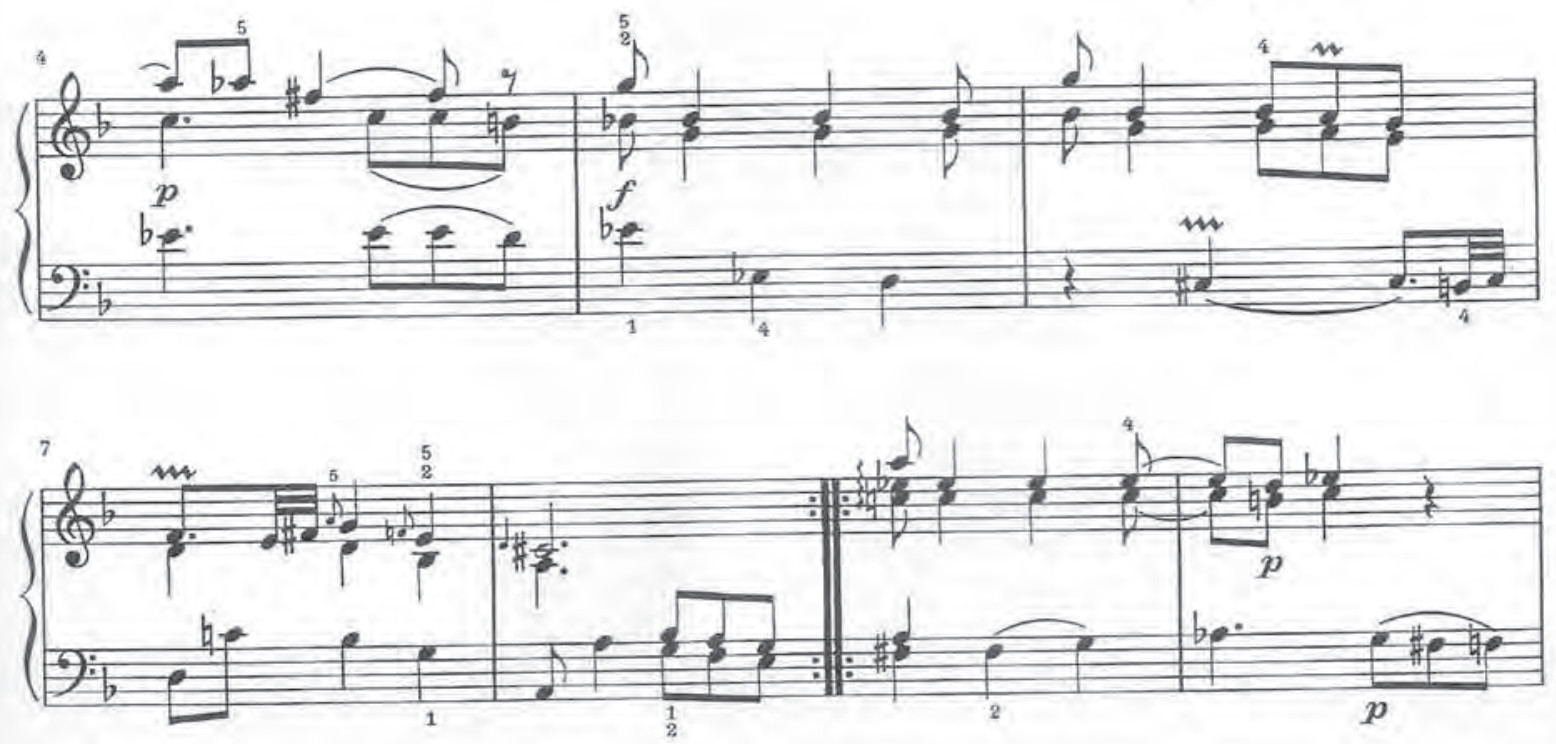

Ex.2: Wilhelm Friedemann, Polonaise, em Ré menor, c.4-10

ta ascendente, especialmente sexta maior, é praticamente uma referência do romantismo. A presença de síncopes é uma característica do ritmo da Polonaise, como descrito por Zamacois. ${ }^{9}$ Terminando a primeira parte, a sequência de três trilos em três tempos seguidos, incluindo um na mão esquerda, além de virtuosística, é um elemento que traz à música a idéia de turbulência (Ex.2).

Na segunda parte, há uma intensificação do cromatismo já presente no início, com uma condução incomum no baixo: 0 acorde de Fá sustenido diminuto previsivelmente resolveria em Sol menor, porém Friedemann surpreende com um encaminhamento que passa pela nota Sol no baixo como quinta de Dó menor, e vai para Lá bemol, com uma appogiatura dupla no compasso 10. Esse procedimento é realizado através da manutenção das notas da parte superior do acorde enquanto o baixo caminha cromaticamente. Procedimento igual acontece nos próximos dois compassos (11 e 12), um tom abaixo, iniciando com o acorde de Mi diminuto, passando por Fá como quinta de Si bemol menor e chegando a Sol bemol maior, também com a presença da dupla appogiatura (Ex. 3).

Os quatro compassos finais seguem com as síncopes características levando à cadência, desta vez com a presença do trilo apenas no baixo, uma vez que a sucinta peça en- 
caminha-se para o final. Chama a atenção a linha do baixo nesta segunda parte: da primeira nota do compasso 9 até a primeira nota do compasso 15 , penúltimo da música, esta caminha impreterivelmente por semitons (exceção à saída do trilo da mão esquerda no compasso 14, onde há um tom entre Dó sustenido e si bequadro, tratando-se no entanto de nota de passagem.). Tal exacerbado cromatismo confere à música um caráter algo angustiante, além de representar uma expansão precoce do sistema tonal (Ex.4).
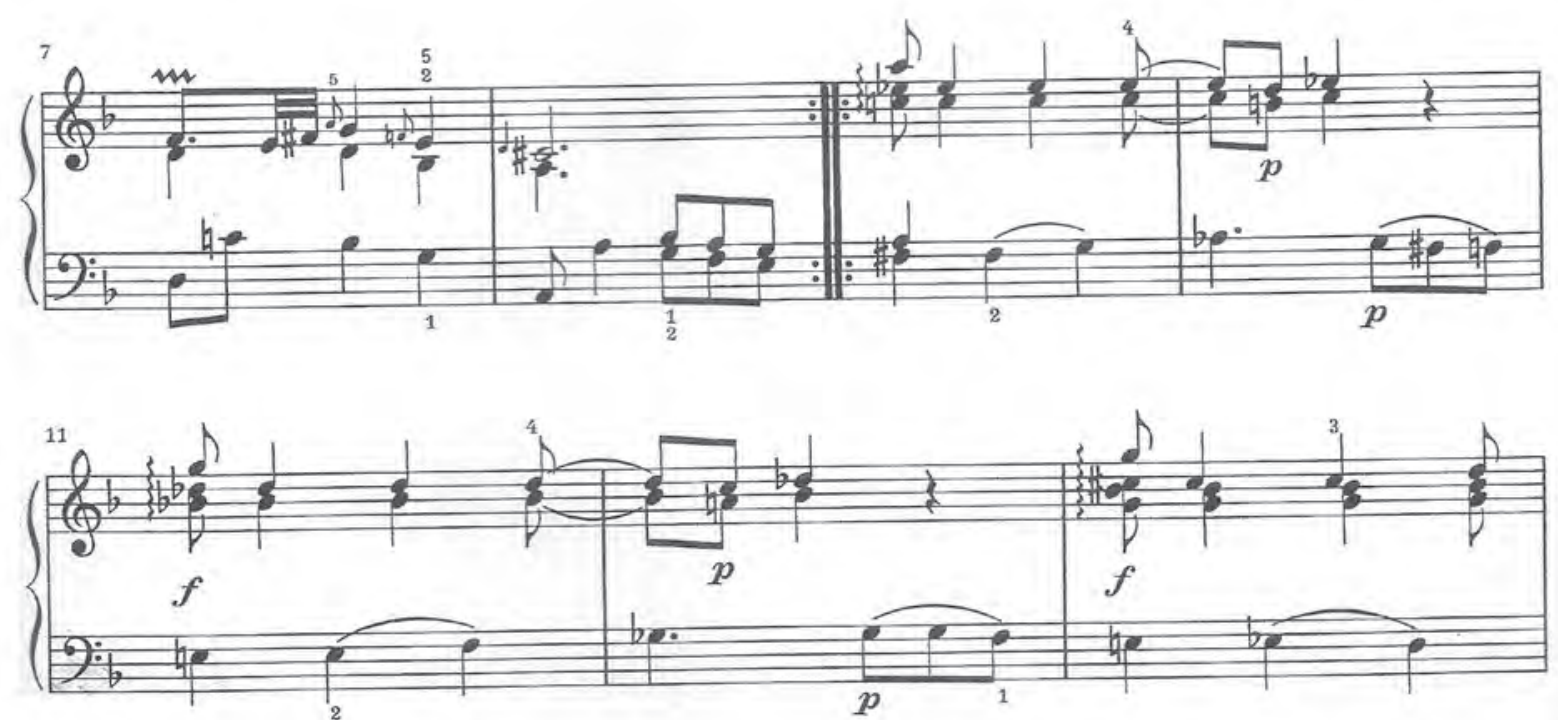

Ex.3: Wilhelm Friedemann, Polonaise, em Ré menor, c.7-13
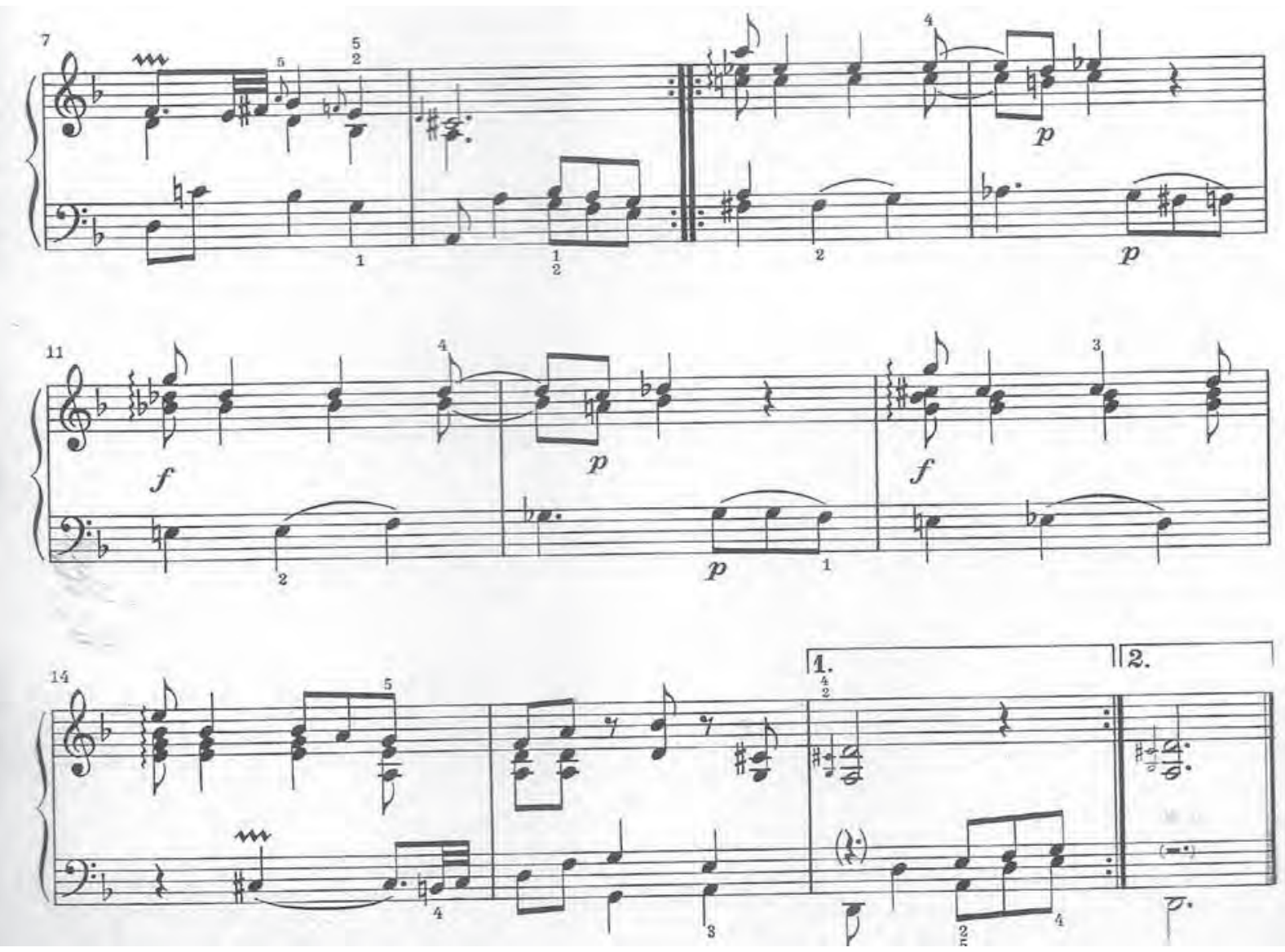

Ex.4: Wilhelm Friedemann, Polonaise, em Ré menor, segunda parte. 


\section{Considerações finais}

Dentro da estética do Empfindsamer Stil, uma pequena peça como a Polonaise em Ré menor (Ex.5) é reveladora de um discurso eloqüente e persuasivo, carregado de drama, típico desta linguagem. 0 cromatismo marcante, os saltos melódicos que parecem suspirar e a marcante sensação de aceleração e desaceleração provocadas pela desorientação harmônica a colocam ao encontro dos anseios expressivos e de demonstração de rebeldia e tormenta próprios dos artistas do Sturm und Drang. Se tais elementos foram premeditadamente utilizados como geradores de sensações, se o compositor tinha consciência de estar enquadrado a uma estética, só é possivel por enquanto especular, uma vez que Wilhelm Friedemann, com sua personalidade controversa, não deixou um legado que permita afirmar tal atitude. Transparece, sem dúvida, na maior parte de sua obra tecladística, a conduta e o temperamento do gênio, essência e ideal do movimento.
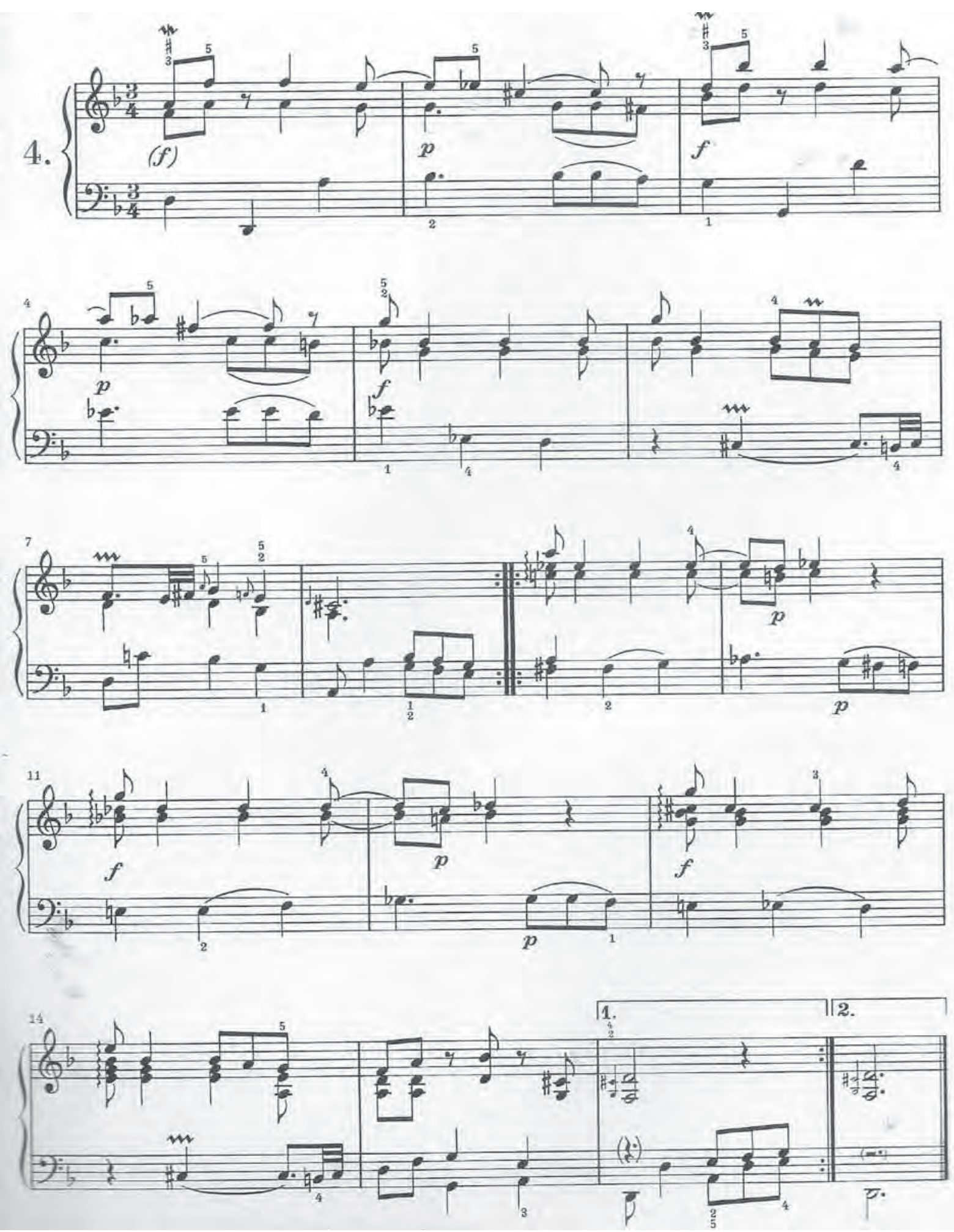

Ex.5: Wilhelm Friedemann, Polonaise no. 4, em Ré menor (Fonte: G. Henle Verlag). 


\section{Referências:}

BACH, Carl Ph. E. Essay on the True Art of Playing Keyboard Instruments. Translated and edited by William J. Mitchell. New York, London: W. W. Norton \& Company, 1949.

BURNEY, Charles. The Present State of Music in Germany, the Netherlands, and United Provinces. The Second Edition, Corrected. London: T. Becket, Strand; J. Robson, New- Bond Street; and G. Robinson, Pasternoster-Row, 1775. Disponivel em http://books.google.com.br/books. Acesso em 27/06/2009.

DOWNS, Philip G. Classical music: the era of Haydn, Mozart and Beethoven. New York: W. W. Norton, 1992.

FALCK, Martin. Wilhelm Friedemann Bach. Sein Leben und seine Werke. Lindau/B: C. F. Kahnt, 1957.

GEIRINGER, Karl et Irène. Bach et sa Famille. Sept Générations de Génies Créateurs. Paris: Editions Buchet/Castel, 1979.

HELM, Eugene. Wilhelm Friedemann Bach. In: The New Grove Bach Family. New York, London: W. W. Norton \& Company, 1983.

PAULY, Reinhard G. Music in the Classic Period. Upper Saddle River, New Jersey: Prentice-Hall, Inc., 2000.

ROSENFELD, Anatol. História do Teatro e da Literatura Alemães. São Paulo: Perspectiva: Editora da Universidade de São Paulo; Campinas: Editora da Universidade Estadual de Campinas, 1993.

SAGHAARD, Terezinha. Os estilos musicais na obra para teclado de C. Ph. E. Bach. Instituto de Artes - UNESP. São Paulo, 2001.

VAN ESS, Donald H. The Heritage of Musical Style. New York: Holt, Rinehart and Winston, Inc., 1970.

YOUNG, Percy M. The Bachs. New York: Thomas Y. Crowell Company, 1970.

WOLLNY, Peter. Wilhelm Friedemann Bach. In: The New Grove Dictionary of Music and Musicians. Second Edition. Vol. 2, p.382-387. London: Macmillan, 2001.

"...welche dem Grössten Concerte gleichen": the Polonaises of Wilhelm Friedemann Bach. In: The Keyboard in Baroque Music. Edited by Christopher Hogwood. NY: Cambridge, 2003.

\section{Partitura.}

W. F. Bach. Zwölf Polonaisen. Prefácio de Andreas Böhnert. München: G. Henle Verlag, 1993.

Gravações

Wilhelm Friedemann Bach Keyboard Works vol. 1. 12 Polonaises, sonata in D major, Fantasia. Robert Hill, fortepiano. Naxos, 2007.

Wilhelm Friedemann Bach Keyboard Works vol. 2. Fantasias und Fugues. Julia Brown, harpsichord. Naxos, 2008.

\section{Notas}

10 movimento pietista, que surgiu na Alemanha em fins do século XVII dentro do luteranismo, foi particularmente importante em Halle, onde a Universidade adotava essa linha. 0 pietismo valorizava a experiência pessoal e subjetiva do crente com Deus e o conhecimento sério e profundo da Bíblia. Para aprofundamento no assunto ver SPENER, Philipp Jacob: Pia desideria - Umkehr in die Zukunft. Brunnen: Verlag Giessen, 1995, ISBN 3-7655-9065-7. Para uma visão geral ver WEBER, Max. A ética protestante e o espírito do capitalismo. São Paulo: Companhia das Letras, 2004.

2 Os dicionários apresentam os termos sensibilidade, sentimentalidade e sentimentalismo como significados de Empfindsamkeit; em português essas três palavras possuem sentidos diferentes, o que certamente também ocorre no alemão. Essencialmente, vem de empfindung (sensação), e refere-se a uma expressão intimista, sensivel, subjetiva.

3 Frantisek Benda, 1709-1786. Compositor tcheco, esteve a serviço de Frederico II na corte prussiana por longo tempo. Seus manuscritos de sonatas para violino contem valiosas informações sobre o estilo em voga naquela corte.

4 His style is so truly cantabile, that scarce a passage can be sound in his compositions, which it is not in the power of the human voice to sing; and he is very affecting a player, so truly pathetic in a Adagio, that several professors have assured me he has frequently drawn tears from them in performing one.

5 De acordo com Andreas Böhnert, no prefácio da edição de G. Henle Verlag de 1993, uma primeira versão impressa das Polonaises foi anunciada em 1765, mas nunca não chegou a ser publicada. De acordo com FALCK (1913), por volta desta data as peças já teriam circulado em versão manuscrita.

6 FALCK, Martin. Wilhelm Friedemann Bach. Sein Leben und seine Werke. Lindau/B.: C. F. Kahnt, 1956. (1a edição 1913).

7 THE KEYBOARD IN BAROQUE EUROPE. Edited by Christoph Hogwood. NY: Cambridge University Press, 2003.

8 Segundo Wollny, mais de trinta manuscritos completos ou parciais dessa coleção circularam nos séculos XVIII e XIX. No caso das Polonaises não existe dúvida quanto a autenticidade da autoria, o que acontece em algumas outras obras de Friedemann, como apontado já na década de 1960 por autores como Newman (NEWMANN, William S. The Sonata in the Classic Era. Chapel Hill: The University of North Carolina Press, 1963).

9 ZAMACOIS, Joaquin. Curso de formas musicales. 4ª Ed. Barcelona, Labor, 1979. 
Stella Almeida Rosa, pianista e cravista, graduou-se em piano pela UNESP (1987) e é Mestre em Música (cravo) pela UNICAMP (2007). É a pianista da Banda Sinfônica do Estado de São Paulo, ligada à divulgação da música brasileira contemporânea, além de musicista regularmente convidada junto à Orquestra Sinfônica do Estado de São Paulo. Como cravista, é membro fundador da Orquestra de Câmara Engenho Barroco, com a qual gravou os CDs "Engenho Barroco", com repertório do Barroco europeu, e uma coleção de três CDs contemplando o "Acervo Musical de Mariana", pelo projeto Petrobrás de Difusão e Restauração de Partituras, e também da Bachiana Chamber Orchestra, cujo primeiro CD foi dedicado às Suítes Orquestrais de J. S. Bach. Dedica-se à execução da música antiga historicamente orientada, participando de diversas formações cameristicas com instrumentos de época ou modernos. Foi professora de baixo contínuo no V Festival "Música nas Montanhas", leciona Música de Câmara na EMESP-Tom Jobim e no Conservatório Souza Lima em São Paulo. É doutoranda em música pela UNICAMP.

Helena Jank concluiu o Doutorado em Música pela Universidade Estadual de Campinas em 1988. Professora titular da mesma universidade, é especialista na interpretação da música barroca historicamente orientada. Desenvolve pesquisa sobre retórica musical do período barroco, a relação textomúsica e o uso de figuras retóricas na expressão dos afetos em música deste período. Em seu projeto de doutorado apresentou uma análise interpretativa das Variações Goldberg de J. S. Bach, obra que se tornou determinante para sua concepção musical. Na graduação lecionou cravo, baixo contínuo, música de câmara e história da música. Na pós-graduação orienta projetos de mestrado e doutorado, ligados às linhas de pesquisa de práticas interpretativas e musicologia histórica. Foi diretora do Instituto de Artes entre 1999 e 2003. 